(SACiUCI study). Crit Care; 14(3):R83. doi:10.1186/cc9008

4. Rhodes A, Evans LE, Alhazzani W, et al (2017) Surviving Sepsis Campaign: International Guidelines for Management of Sepsis and Septic Shock.Intensive Care Med; 43(3):304-377.

5. Prachanukool $T$, Sanguanwit $P$, Thodamrong

F, Suttapanit K (2021). The 28-Day Mortality
Outcome of the Complete Hour-1 Sepsis Bundle in the Emergency Department. Shock; 56(6):969.

6. Zou $Y$, Liao $L$, Wei $Z$, et al (2021). A 1-hour Bundle compliance survey of the "Surviving Sepsis Campaign" and its impact on the prognosis of sepsis patients: a multicenter, prospective observational cohort study. Zhonghua Wei Zhong Bing Ji Jiu Yi Xue; 33(6):671-675.

\title{
TỶ LÊ HIỆN MẮC VÀ TỶ LÊ MẮC MỚI ĐộNG KINH TẠI TỈNH AN GIANG
}

\section{TÓM TẮT}

Đă̆t vấn đề: Đông kinh là vấn đề sức khỏe quan trọng xảy ra ở moi xã hôi trên toàn thế giới, không phân biệt về giới tính, tuổi tác và dân tộc. Các nghiên cứu dịch tễ học rất quan trọng để cung cấp nền tảng chung và xác định các yếu tố liên quan đến bênh. Mục tiêu của nghiên cứu chúng tôi là xác đinh tỷ lệ hiển mắc và tỷ lệ mắc mới động kinh tại tỉnh An Giang. Đối tượng và phương pháp nghiên: Nghiên cứu cắt ngang trên 160.236 cư dân trên địa bàn 24 xã, phường của tỉnh An Giang, chúng tôi phát hiện có 864 bệnh nhân động kinh, thời gian nghiên cứu từ tháng 01 năm 2020 đến tháng 12 năm 2020. Kết quả nghiên cứu: Tỷ lệ hiện mắc động kinh của tỉnh An Giang là 539/100.000 dân, trong đó động kinh hoạt động là 108/100.000 dân. Trong số 864 bệnh nhẩn động kinh được chọn vào mẫu nghiên cứu, kết quả cơn động kinh toàn thể chiếm 68,2\%, cơn động kinh cục bộ chiếm $27,4 \%$, cơn động kinh không phân loại chiếm 4,4\%. Giới nam chiếm 63,2\% nhiều hơn nữ, trình độ học vấn cấp một chiếm $42,5 \%$, nguyên nhân động kinh do u não chiểm 2,3\%, chấn thương sọ não chiếm $8,9 \%$, đột quị não chiếm $21,3 \%$. Kết luận: Tỷ lê hiện mắc động kinh trên cộng đồng dân cư tỉnh An Giang là 539/100.000 dân. Tỷ lệ mắc mới động kinh hàng năm là 108/100.000 dân.

\section{SUMMARY}

\section{STUDY ON THE PREVALANCE AND} INCIDENCE OF EPILEPSY FOR THE POPULATION IN THE AN GIANG PROVINCE

Background: Epilepsy is an important healthcare problem that occurs in every society across the world regardless of any difference in sex, age and ethnicity. Epidemiologic studies are important for providing a common ground and determining the factors associated with the disease. The objective of our study was to determine the prevalence and incidence of

${ }^{1}$ Bệnh viện Đa khoa Trung tâm An Giang ${ }^{2}$ Oai hoc Y dước Thành phố Hồ Chí Minh. Chịu trách nhiệm chính: Mai Nhật Quang Email: bsquangag@gmail.com

Ngày nhận bài: 10.9.2021

Ngày phản biên khoa hoc: 29.9.2021

Ngày duyệt bài: 10.11.2021

\section{Mai Nhật Quang1, Lê Văn Tuấn²}

epilepsy for the population in the An Giang province. Patients and methods: Cross-sectional study design including 864 persons who admitted to An giang hospital from February $1^{\text {st }} 2020$ to August 31 th 2020. Results: The study was conducted on 160.236 residents in An Giang province, the results show that the overall prevalence of epilepsy in An Giang province is $539 / 100.000$ people, of which active epilepsy is 108/100.000 people. Among 864 epilepsy patients selected into the study sample, the results of generalized seizures accounted for $68,2 \%$, partial seizures accounted for $27,4 \%$, and unclassified seizures accounted for $4,4 \%$. Males accounted for $63,19 \%$ more than females, primary education level accounted for $42,5 \%$, epilepsy caused by brain tumors accounted for $2,3 \%$, traumatic brain injury accounted for $8,9 \%$, stroke accounted for $21,3 \%$. Conclusion: The prevalence of epilepsy in the population of An Giang province is $539 / 100.000$ people. The annual incidence of epilepsy is $108 / 100.000$ people. Epilepsy are more common in rural and urban areas than in mountainous areas.

\section{I. ĐĂT VẤN ĐỀ}

Động kinh là một trong những rối loạn thần kinh mãn tính và phổ biến nhất có thể ảnh hưởng đến từng cá nhân ở mọi lứa tuổi. Đã có khoảng 50 triệu người mắc bệnh động kinh trên toàn thế giới vào năm 2016. Gánh nă̆ng bênh tât toàn cầu năm 2010 của WHO nghiên cứu xểp hạng động kinh là rối loạn thần kinh nặng thứ hai về khuyết tật. Động kinh có thể ảnh hưởng xấu đến chất lượng cuộc sống của mỗi cá nhân vì sự hiện diện của chấn thương thể chất liên quan đến động kinh, không có khả năng làm việc hoặc đi học, tác dụng phụ của điều trị thuốc, các bệnh đi kèm, tình trạng suy nhược tâm lý xã hội, phát triển thành cơn động kinh kháng thuốc và tử vong sớm[8].

Các nghiên cứu về tỷ lệ hiện mắc và tỷ lệ mắc mới động kinh sẽ cung cấp các dữ liệu làm phong phú thêm hiểu biết của chúng ta về bản chất của động kinh, làm cơ sở cho việc hoạch định kế hoạch chăm sóc sức khỏe cho các bệnh 
nhân động kinh và dự phòng các yếu tố nguy cơ làm giảm tỷ lệ mắc động kinh. Chúng tôi tiến hành nghiên cứu đề tài: "Tỷ lệ hiện mắc và tỷ lệ mắc mới động kinh tại tỉnh An Giang" với mục tiêu:

1. Tỷ lề hiện mắc và tỷ lệ mắc mới động kinh tại tỉnh An Giang.

2. Đặc điểm dân số họ động kinh tại tỉnh An Giang.

Chúng tôi hi vọng kết quả nghiên cứu này sẽ góp phần phong phú hơn về dữ liệu động kinh tại khu vực đồng bằng sông Cửu Long cũng như của cả nước.

\section{II. ĐỐI TƯợNG VÀ PHƯƠNG PHÁP NGHIÊN CỨU}

Đối tượng nghiên cứu: Cộng đồng dân cư 24 phường, xã nghiên cứu trên địa bàn tỉnh An Giang.

Tiêu chuẩn chọn bệnh: Bệnh nhân được chẩn đoán động kinh theo tiêu chuẩn liên đoàn động kinh quốc tế, khi có ít nhất hai cơn động kinh không có yếu tố kích gợi xảy ra cách nhau $>24$ giờ.

Tiêu chuẩn loại trừ: Các trường hợp co giật cấp không phải động kinh như hạ natri máu, tăng đường huyết, hạ đường huyết.

Phương pháp nghiên cứu: Nghiên cứu cắt ngang mô tả tiến cứu.

Thời gian nghiên cứu: Thời gian nghiên cứu từ tháng 01 năm 2020 đến 31 tháng 12 năm 2020.

Địa điểm nghiên cứu: Cộng đồng dân cư tỉnh An Giang.

Cỡ mẫu nghiên cứu: được tính theo công thức

$$
N=\frac{Z_{(1-\infty / 2)}^{2} X P(1-P)}{d^{2}}
$$

Trong đó: N: Số mẫu cân nghiên cứu;

$Z^{2}(1-a / 2)=1,96$ với khoảng tin cậy $95 \%$; $\varepsilon$ : sai số tương đối 0,$1 ; \mathrm{d}^{2}=(\varepsilon \times \mathrm{P})^{2}=(0,1 \times 0,005)^{2}$.

$$
\mathrm{N}=\frac{1,96^{2} X 0,005(1-0,05)}{(0,1 X 0,005)^{2}}=76.448
$$

Do chon mẫu theo kỹ thuật chọn mẫu cum nên cỡ mẫu cần phải chọn bằng cỡ mẫu tính được nhân 2 lần, do đó cỡ mẫu cần nghiên cứu là 152.896 người.

Phương pháp phân tích và xử lý số liệu: Số liệu được xử lý trên phần mềm SPSS 22.0.

\section{KẾT QUẢ NGHIÊN CứU}

Trong thời gian nghiên cứu từ tháng 01 năm 2020 đến 31 tháng 12 năm 2020, chúng tôi tiến hành sàng lọc 160.236 người trong dân số nghiên cứu, chúng tôi chọn được 864 bệnh nhân thỏa điều kiện vào mẫu nghiên cứu, tỳ lệ hiện mắc động kinh 539/100.000 dân, trong đó động kinh hoạt động là 108/100.000 dân.

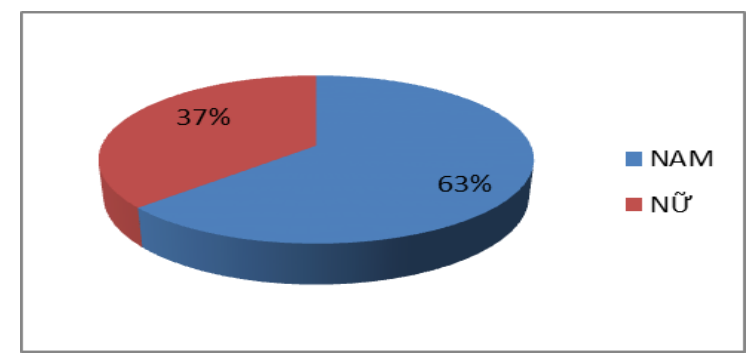

Hình 1. Tỷ lê mắc động kinh theo giới

Nhận xét: Trong nghiên cứu số bệnh nhân nam (546/864) chiếm $63 \%$, số bệnh nhân nữ (318/864) chiếm $37 \%$.

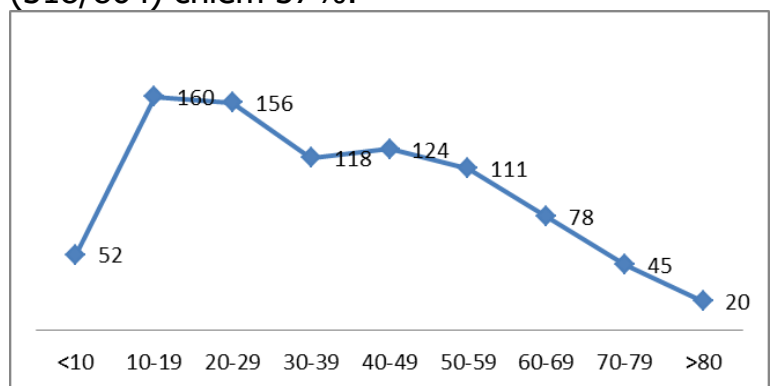

Hình 2. Nhóm tuổi mắc động kinh

Nhận xét: Nhóm tuổi 10-19 mắc động kinh nhiêu nhất, sau đó tỷ lệ mắc động kinh giảm dân theo thời gian, trên 80 tuổi tỷ lệ mắc động ít nhất.

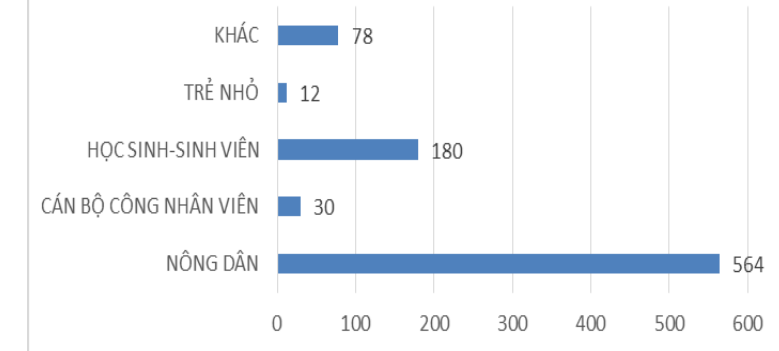

Hinh 3. Tỷ lệ mắc động kinh theo nghề nghiệp Nhận xét: Trong nghiên cứu nhóm mắc bệnh có nghề nghiệp nông dân chiếm đa số 464/864, tiếp theo là học sinh-sinh viên có 180/864, cán bộ công nhân viên 30/864.



\section{Hình 4. Tỷ lệ mắc động kinh theo khu vực cư trú}

Nhận xét: Tỷ lệ mắc động kinh nhiều ở khu vực nông thôn $60 \%$, sau đó là khu vực thành thị và̀ cuối cùng là khu vực miền núi. 


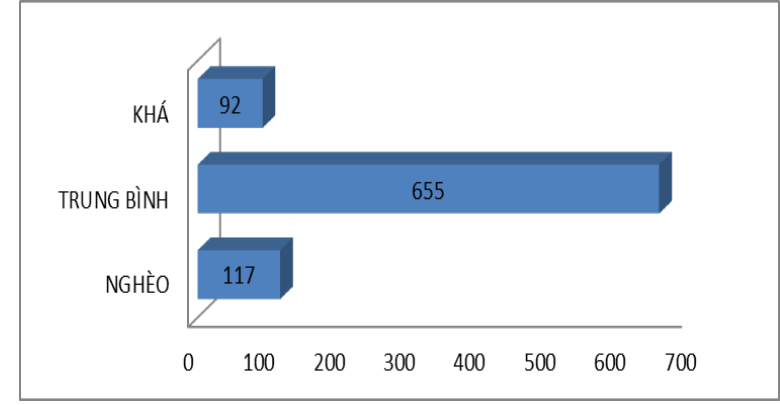

Hình 5. Tình trạng kinh kế ở bệnh nhân mắc đông kinh

Nhận xét: Trong số các gia đình bệnh nhân động kinh có thu nhận trung bình chiếm đa số 655/864.

Bảng 1. Thời gian mang bênh động kinh

\begin{tabular}{|c|c|c|}
\hline $\begin{array}{c}\text { Thời gian mang } \\
\text { bệnh }\end{array}$ & $\begin{array}{c}\text { Số bệnh } \\
\text { nhẩn }\end{array}$ & Tỷ lệ \\
\hline Dưới 1 năm & 173 & $20 \%$ \\
\hline $1-5$ năm & 349 & $40,4 \%$ \\
\hline $6-10$ năm & 260 & $30,1 \%$ \\
\hline Trên 10 năm & 82 & $9,5 \%$ \\
\hline Tống & $\mathbf{8 6 4}$ & $\mathbf{1 0 0 \%}$ \\
\hline
\end{tabular}

Nhân xét. Thời gian mang bênh động kinh từ 1 đến 5 năm chiếm đa số $40,4 \%$, thời gian mang bệnh từ 6-10 năm chiếm 30,1\%.

Bảng 2. Tỷ lệ hiện mắc động kinh liên quan trinh độ học vấn

\begin{tabular}{|c|c|c|c|}
\hline Trình độ học vấn & Số trường hợp động kinh & Tỷ lệ \% & Khoảng tin cậy 95\% \\
\hline Mù chữ & 160 & $18,5 \%$ & $16-21,4 \%$ \\
\hline Cấp 1 & 367 & $42,5 \%$ & $39,1-45,7 \%$ \\
\hline Cấp 2 & 211 & $24,4 \%$ & $21,4-27,3 \%$ \\
\hline Cấp 3 & 88 & $10,2 \%$ & $8,2-12,3 \%$ \\
\hline Cao đăng - Đại học & 38 & $4,4 \%$ & $3,1-5,9 \%$ \\
\hline
\end{tabular}

Nhận xét: Các bệnh nhân động kinh có trình độ học vấn cấp 1 là cao nhất chiếm $42,5 \%$, trình độ học vấn cấp 2 chiếm $24,4 \%$, trình độ cấp 3 chiếm 10,2\%, trình độ cao đẳng đại học chiếm $4,4 \%$.

Bảng 3. Phân loại động kinh theo giới tính

\begin{tabular}{|c|c|c|c|}
\hline Loại cơn động kinh & Tống N(\%; CI 95\%) & Nam N(\%; CI 95\%) & Nũ̃ N(\%; CI 95\%) \\
\hline Toàn thể & $589(68,2 \% ; 64,9-71,2)$ & $374(68,5 \% ; 64,3-72,4)$ & $215(67,6 \% ; 62,3-72,8)$ \\
\hline Cục bộ & $237(27,4 ; 14,4 \%-30,7)$ & $145(26,6 \% ; 22,8-30,3)$ & $92(28,9 \% ; 24-33,7 \%)$ \\
\hline Không phần loại & $38(4,4 \% ; 3-5,8)$ & $27(4,9 \% ; 3,3-6,8)$ & $11(3,5 \% ; 1,5-5,6)$ \\
\hline
\end{tabular}

Nhận xét: Trong nghiên cứu loại cơn động kinh toàn thế là chủ yếu chiếm $(68,2 \%)$, sau đó là loại cơn động kinh cục bộ chiếm 27,4\% và động kinh không phân loại chiếm 4,4\%.

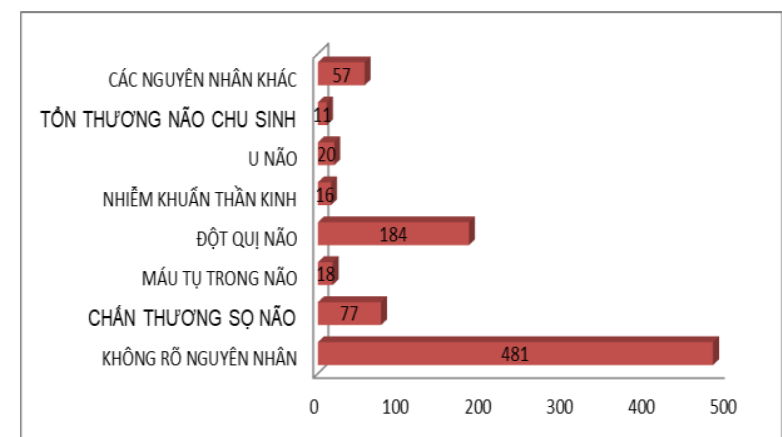

Hình 6. Nguyên nhân gây đông kinh

Nhận xét: Trong các nguyên nhân động kinh khảo sát được, đột quị não có 184/864 trường hợp, u não có 20/864 trường hợp, chấn thương sọ não có 77/864 trường hợp.

\section{BÀN LUÂN}

Tuổi: Trong nghiên cứu của chúng tôi, tuổi trung bình của các bệnh nhân động kinh là $37,03 \pm 20,22$ tuổi. Khi xem xét theo nhóm tuổi, nhóm tuổi dưới 40 có tỷ lệ bệnh nhân mắc nhiều hơn so với nhóm tuổi trên 40 . Nhóm tuổi có tỷ lệ mắc cao nhất là nhóm tuổi từ 10-19 tuổi. Nghiên cứu của tác giả Nguyễn Anh Tuấn cho thấy nhóm tuổi 35-44 chiếm tỷ lệ cao nhất 25,5\%[5].

Giới: Tỷ lệ mắc động kinh ở giới nam nhiều hơn giới nữ ở mọi lứa tuổi và ở tất cả các loại động kinh, điều này có lẽ là do nam giới dễ bị các yếu tố nguy cơ động kinh so với giới nữ như chấn thương đầu do di chuyển nhiều trên đường dễ bị tai nạn giao thông, làm các công việc nặng nhọc dễ bị tai nạn sinh hoạt cũng như tai nạn lao động. Kết quả nghiên cứu của chúng tôi cũng tương tự như nghiên cứu của tác giả Nguyễn Anh Tuấn Và Nguyễn Văn Hướng[4, 5].

Cư trú: Nghiên cứu của chúng tôi cho thấy tỷ lệ mắc động kinh ở thành thị thấp hơn so với nông thôn. Điều này có thể lý giải vì khu vực thành thị có điều kiện kinh tế, văn hóa, y tế, dẩn trí và mức sống cao hơn so với khu vực nông thôn và miền núi do vậy người dân được chăm sóc y tế tốt hơn, giáo dục tốt hơn, dân trí cao hơn nên tỷ lệ mắc động kinh thấp hơn so với các ku vực khác. Khu vực nông thôn và miền núi do kinh tế khó khăn, dân trí chưa cao, trang thiết bị y tế nghèo nàn, điều kiện vệ sinh còn kém làm tăng nguy cơ các bệnh viêm não, viêm màng não, nhiễm ký sinh trùng,...việc quan tâm chăm 
sóc sức khỏe ban đầu chưa tốt, khi mắc bệnh còn điều trị theo dân gian và không tuân thủ điều trị làm cho tỷ lệ mắc động kinh cao hơn so với các khu vực khác.

Trinh độ học vấn: Trong nghiên cứu của chúng tôi, tỷ lệ mắc động kinh ở nhóm bệnh nhân có trình đô hoc vấn tiểu hoc chiếm cao nhất 367/864 (42,5\%), nhóm người có trình độ cấp hai chiếm 211/864 (24,4\%), nhóm người bệnh có trình độ cấp ba chiếm 88/864 (10,2\%), nhóm người có trình độ cao đắng - đại học chiếm 38/864 (4,4\%), nhóm bệnh nhân mù chữ chiếm 160/864 (18,5\%). Nghiên cứu của tác giả Nguyễn Văn Hướng tại xã Phù Linh cho thây nhóm người không biết chữ cao nhất chiếm $24 \%$, nhóm người có trình độ tiểu học chiếm $9,3 \%$, trình độ trung học cơ sở chiếm 4,8\%, trung học phổ thông trở lển chiếm 5,5\%[4].

Nhóm tuổi: Trong nghiên cứu của chúng tôi, tại cộng đồng dân cư tỉnh An Giang nhóm có thời gian mang bệnh động kinh từ 1 đến 5 năm chiếm tỷ lệ cao nhất 349/864 (40,4\%), thời gian mang bênh động kinh dưới môt năm chiếm 173/864 (20\%), thời gian mang bệnh động kinh từ 6 đến 10 năm chiếm 260/864 (30,1\%), thời gian mang bênh trên 10 năm chiếm 82/864 (9,5\%). Nghiên cứu của chúng tôi tương tự như nghiên cứu của tác giả Dương Huy Hoàng tại tỉnh Thái Bình, nhóm tuổi từ 1 đến 5 tuổi chiếm tỷ lệ $53 \%$. Thời gian mang bệnh từ 1 đến 5 năm cao có thể do người dân thiếu kiến thức về bệnh động kinh, cũng như mặt cảm về bệnh, đặc biệt ở vùng nông thôn và miền núi nhân dân còn tồn tại những quan niệm sai lầm về bệnh tật đặc biệt là bệnh động kinh làm cho người thân sợ hãi che che dấu. Khi bệnh nặng hoặc có nhiều cơn động kinh thì người thân mới đưa bệnh nhân đến cơ sở y tế. Ngoài ra, còn phụ thuộc vào trình độ và mạng lưới y tế cơ sở nơi bệnh nhân sinh sống.

Loại động kinh: Kết quả nghiên cứu của chúng tôi cho thây động kinh toàn thể chiếm 589/864 $(68,2 \%)$, động kinh cục bộ chiếm 237/864 (27,4\%), động kinh không phân loại chiếm 38/864 $(4,4 \%)$. Nghiên cứu của tác già Nguyễn Thúy Hường tỷ lệ động kinh toàn thể chiếm 74,8\%. Loại cơn động kinh toàn thể trong nghiên cứu của chúng tôi tương tự như nghiên cứu của tác giả Dương Huy Hoàng, động kinh toàn thể chiếm 69,4\%[2]. Nghiên cứu của tác giả Pakdaman và cộng sự tại Iran khi khảo sát tỷ lệ động kinh trên 68.035 dân trên toàn quốc cho thấy tỷ lệ mắc động kinh là 9,5/1000 dân, động kinh cục bộ chiếm $59,3 \%$, động kinh toàn thể chiếm $38 \%$, động kinh không phân loại chiếm 2,7\%[9].
Nguyên nhân động kinh: Trong nghiên cứu của chúng tôi có $77 / 864$ trường hợp động kinh có tiền căn chấn thướng sọ não chiếm $8,9 \%$. Nghiên cứu của tác giả Dương Huy Hoàng nguyên nhân chấn thương sọ não chiếm 23,9\%, tác giả Nguyễn Thúy Hường động kinh do chấn thương sọ não chiếm $11,5 \%[2,3]$. Trong nghiên cứu của chúng tôi u não có 20/864 trường hợp chiếm 2,3\%, nghiên cứu của tác giả Dương Huy Hoàng u não chiếm 4,1\%[2]. Điều khác biệt này là do các tác giả nghiên cứu động kinh trên người lớn và nghiên cứu trong bệnh viện. Các bệnh nhân mắc động kinh đều được chụp cắt lớp vi tính so não hoặc chụp cộng hưởing từ'.

Nghiển cứu cho thẩy tỷ lệ hiện mắc động kinh chung của tỉnh An Giang là 539/100.000 dân, trong đó động kinh hoạt động là 108/100.000 dân. Ở Việt Nam, đã có các nghiên cứu dịch tễ học động kinh cộng đồng đã được thực hiện chủ yếu tại tỉnh khu vực miên Bắc như nghiền cứu của tác giả Nguyễn Anh Tuấn, tỷ lệ mắc động kinh tại cộng đồng dân cư huyện $B a$ Vì là $4,4 / 1000$ dẩn[5]. Nghiên cứu của tác giả Nguyễn Văn Doanh tại cộng đồng dân cư huyện Gia Bình tỉnh Bắc Ninh, tỷ lệ mắc động kinh tại vùng dân cư này là $8,4 \%$ và tỷ lê độnh kinh hoạt động là $6,6 \%$ o[1].

Trong phân tích tổng hợp của tác giả Fiest KM và cộng sự năm 2017 cho thây tỷ lệ mắc mới động kinh chung là 61,4 trên 100.000 người-năm (KTC 95\% 50,7-74,4)[7]. Tỷ lệ mắc bệnh cao hơn ở các nước thu nhập thấp /trung bình so với các nước có thu nhập cao, 139,0 (KTC 95\% 69,4-278,2) so với 48,9 (KTC 95\% 39,0-61,1). Điều này có thể được giải thích bởi cấu trúc khác nhau của quần thể có nguy cơ và tiếp xúc nhiều hơn với các yếu tố nguy cơ chu sinh, tỷ lệ nhiễm trùng thần kinh trung ương và chấn thương sọ não cao hơn ở các nước có thu nhập thấp[6].

Nghiên cứu cho thây tỷ lệ hiện mắc động kinh chung của tỉnh An Giang là 539/100.000 dân, trong đó động kinh hoạt động là 108/100.000 dân. Ở Việt Nam, đã có các nghiên cứu dịch tễ học động kinh cộng đồng đã được thực hiện chủ yểu tai tỉnh khu vực miên Bắc như nghiển cứu của tác giả Nguyễn Anh Tuấn, tỷ lệ mắc động kinh tại cộng đồng dân cư huyện $B a$ Vì là 4,4/1000 dânn[5]. Nghiên cứu của tác giả Dương Huy Hoàng tại công đồng dân cư tỉnh Thái Bình, tỷ lệ mắc động kinh tại vùng dân cư này là $5,6 \%$ và tỷ lệ động kinh hoạt động là 5,3\%o[2].

\section{KẾT LUÂNN}

Qua nghiên cứu 160.236 cư dân tại tỉnh An Giang, có 864 bệnh nhân động kinh, tỷ lệ hiện 
mắc động kinh là 539/100.000 dân, tỷ lệ mắc mới là 108/100.000 dân. Nhóm tuổi 10-19 mắc động kinh nhiêu nhất, động kinh không rõ nguyên nhân chiếm đa số, nguyên nhân động kinh thường gặp nhất là đột quị não. Loại cơn động kinh thường gặp là động kinh toàn thể.

\section{TÀl LIẸU THAM KHẢO}

1. Nguyễn Văn Doanh. (2007). Nghiên cứu một số đắc điểm dịch tễ học và điêu trị động kinh ở cộng đồng dân cư thuộc huyện Gia Bình tỉnh Bắc Ninht.

2. Dương Huy Hoà̃ng. (2009). Nghiên cứu một số đặc điểm dịch tễ, lâm sàng động kinh, tình hình quản lý bệnh nhân động kinh tại tỉnh Thái Bình. Luân án Tiến sĩ Y hoc năm 2009.

3. Nguyển Thúy Hường. (2001). Nghiên cứu một sổ đặc điểm dịch tễ và tình hình điều trị động kinh taai cộng đồng tỉnh Hà Tây, Luận án Tiến sĩ Y học, Học viện Quân y.

4. Nguyến Văn Hướng. (2003). Dịch tễ động kinh tại xã Phù Linh, huyện Sóc Sơn, Hà Nội, Luận văn Bác sĩ Đại học Y Hà Nội.

5. Nguyến Anh Tuấn. (2007). Tỷ lệ động kinh ở huyên Ba Vì.

6. Beghi E, Hesdorffer D (2014). Prevalence of epilepsy an unknown quantity. Epilepsia. 2014 Jul; 55(7): 963-7.

7. Fiest KM, Sauro KM, Wiebe S, Patten SB, Kwon CS, Dykeman J, et al (2017). Prevalence and incidence of epilepsy: A systematic review and meta-analysis of international studies. Neurology. 2017 Jan; 88(3): 296-303.

8. Mohammad Q D, Saha N C (2020). Prevalence of epilepsy in Bangladesh: Results from a national household survey. 5 (4), 526-536.

\title{
ĐĂC ĐIỂM LÂM SÀNG VÀ HUYẾT HOC THEO GEN ĐÔ̂T BIẾN CỦA BÊ̂NH NHI THALASSEMIA TẠI BỆNH VIỆN TRẺ EM HẢI PHÒNG
}

\author{
Đỗ Thị Quỳnh Mai*, Nguyễn Ngọc Sáng**, Bạch Thị Như Quỳnh**
}

\section{TÓM TẮT}

Mục tiêu: Mô tả đặc điểm lâm sàng và huyết học theo đột biến gen phổ biến của bệnh thalassemia ở trẻ em. Đối tượng: 83 bệnh nhi Thalassemia điều trị tại bệnh viện Trẻ em Hải Phòng từ 01/01/2015 đển $31 / 12 / 2020$. Phương pháp: Nghiên cứu mô tả một loạt ca bệnh. Kết quả: Biểu hiên lâm sàng thể athalassemia chủ yếu ở đột biến HbCs - SEA, HbCs và SEA - C2.delT. Bệnh nhi a-thalassemia thiếu máu nhe và trung bình ( $\mathrm{Hb}$ trung bình đột biến 1 gen là $93,8 \pm 10,4 \mathrm{~g} / \mathrm{l} ; 2$ gen là $92,4 \pm 13,5 \mathrm{~g} / \mathrm{l}$ và 3 gen là $87,2 \pm 8,5 \mathrm{~g} / \mathrm{l})$. Tỉ lệ HbA1giảm nhe $(83,9-94,2 \%), \mathrm{HbA} 2$ bình thường, $\mathrm{HbH}$ tăng (từ $7,8 \pm 2,5 \%$ đến $11,6 \pm 7,3 \%)$. Các triệu chứng ở bệnh nhi $\beta$ thalassemia biểu hiện ở thể $\beta^{0} \beta^{0}(100 \%)$ và $\beta^{0} \beta^{E}$ $(76,6 \%-96,2 \%)$, ít hơn ở thể $\beta^{0} \beta(9,5 \%-33,3 \%)$. Bệnh nhi $\beta$-thalassemia thiếu máu từ trung bình ( $\mathrm{Hb}$ trung bình thể $\beta^{0} \beta^{0}$ là $68,2 \pm 12,5 \mathrm{~g} / \mathrm{l}$ và $\beta^{0} \beta^{\mathrm{E}}$ là $79,8 \pm 14,2 \mathrm{~g} / \mathrm{l})$ đến nhẹ $(101,7 \pm 15,2 \mathrm{~g} / \mathrm{l})$. Thành phân $\mathrm{Hb}$ thay đối: Thể $\beta^{0} \beta^{0}, \mathrm{HbA} 1$ giảm $(35,7 \pm 12,2 \%), \mathrm{HbF}$ tăng $(60,8 \pm 23,7 \%) ;$ Thể $\beta^{0} \beta^{E}$ có $\mathrm{HbA} 1$ giảm $(26,1 \pm 14,1 \%) ; \mathrm{HbF}$ tăng $(38,5 \pm 14,6 \%)$ và $\mathrm{HbE}$ tăng $(38,3 \pm 15,7 \%) ;$ Đột biến $\beta^{0} \beta$, có HbA1 giảm $(73,7 \pm 26,5 \%) ; \quad H b \dot{2} 2$ tăng $(3,8 \pm 1,5 \%)$ và $\mathrm{HbF}$ tăng $(21,2 \pm 4,3 \%)$. Kết luận: a-thalassemia ít biểu hiện trên lâm sàng. Huyết học thay đổi tùy số gen tổn thương. Đăc trưng điện di $\mathrm{Hb}$ với tî lệ $\mathrm{HbH}$ tăng. Lâm sàng và chỉ số huyết học của bệnh nhân $\beta$-thalassemia

*Bệnh viện Trẻ Em Hải Phòng

**Trường Đai họ Y Dược Hải Phòng

Chịu trách nhiệm chính: Đố Thị Quỳnh Mai

Email: quynhmaikid@gmail.com

Ngày nhận bài: 14.9.2021

Ngày phản biên khoa học: 4.11 .2021

Ngày duyệt bài: 16.11.2021 thay đổi nhiều ở $\beta^{0} \beta^{0}$ và $\beta^{0} \beta^{E}$ hơn $\beta^{0} \beta$. Thành phần $\mathrm{Hb}$ thay đổi với $\mathrm{HbA}$ giảm, tăng cao $\mathrm{HbF}$ và có thể xuất hiên $\mathrm{HbE}$. Có sự liên quan giữa kiểu gen đột biến và kiểu hình ở bệnh nhi thalassemia.

Tư khóa: Thalassemia, đột biến gen, trẻ em.

\section{SUMMARY}

CLINICAL AND HEMATOLOGICAL

CHARACTERISTICS ACCORDING TO GENE MUTATIONS OF THALASSEMIA IN CHILDREN AT HAI PHONG CHILDREN'S HOSPITAL

Objectives: To describe clinical and hematological characteristics according to gene mutations of thalassemia in children. Subjects: 83 Thalassemia pediatric patients treated at Haiphong Children's Hospital from January 1, 2015, to December 31, 2020. Methods: Case-series study. Results: Clinical manifestations of a-thalassemia are mainly in HbCs SEA, HbCs and SEA - C2.delT mutations. Pediatric athalassemia mild-moderate anemia (mean $\mathrm{Hb}$ mutation of 1 gene: $93.8 \pm 10.4 \mathrm{~g} / \mathrm{l} ; 2$ genes: $92.4 \pm 13.5 \mathrm{~g} / \mathrm{l}$ and 3 genes: $87.2 \pm 8.5 \mathrm{~g} / \mathrm{l})$. The rate of HbA1 decreased slightly $(83.9-94.2 \%), \mathrm{HbA} 2$ was normal, $\mathrm{HbH}$ increased (from $7.8 \pm 2.5 \%$ to $11.6 \pm 7.3 \%)$. Symptoms in children with $\beta$-thalassemia were expressed in $\beta^{0} \beta^{0}(100 \%)$ and $\beta^{0} \beta^{E}(76.6 \%$ $96.2 \%)$, less so in $\beta^{0} \beta(9.5 \%-33.3 \%)$. Pediatric $\beta$ thalassemia anemia ranged from moderate (mean $\mathrm{Hb}$ of $\beta^{0} \beta^{0}$ body was $68.2 \pm 12.5 \mathrm{~g} / \mathrm{l}$ and $\beta^{0} \beta^{\mathrm{E}}$ was $79.8 \pm 14.2 \mathrm{~g} / \mathrm{l})$ to mild $(101.7 \pm 15.2 \mathrm{~g}) \mathrm{ll})$. $\mathrm{Hb}$ composition changed: The $\beta^{0} \beta^{0}, \mathrm{HbA1}$ decreased $(35.7 \pm 12.2 \%)$, HbF increased $(60.8 \pm 23.7 \%)$; The $\beta^{0} \beta^{E}$ form has decreased $\mathrm{HbA1}(26.1 \pm 14.1 \%)$; $\mathrm{HbF}$ increased $(38.5 \pm 14.6 \%)$ and $\mathrm{HbE}$ increased $(38.3 \pm 15.7 \%) ;$ Mutant $\beta^{0} \beta$ with reduced HbA1 $(73.7 \pm 26.5 \%) ; \mathrm{HbA} 2$ increased $(3.8 \pm 1.5 \%)$ and $\mathrm{HbF}$ increased $(21.2 \pm 4.3 \%)$. Conclusion: a-thalassemia 